\title{
Quality assurance program for Angra 1 licence renewal and long-term operation
}

\author{
Morghi $^{a}$.Y., Mesquita ${ }^{a}$ A.Z., Baliza ${ }^{b}$ X.Y., Amaral ${ }^{b}$ J.A. \\ ${ }^{a}$ CDTN - Centro de Desenvolvimento da Tecnologia Nuclear, Campus da UFMG, Av. Pres. \\ Antonio Carlos, 6627 Pampulha, Belo Horizonte -MG, 31270-901 \\ ${ }^{b}$ Central Nuclear Almirante ÁLVARO Alberto Rodovia Procurador Haroldo Fernandes Duarte \\ BR101/RJ. Itaorna dos Reis - RJ, CEP: 23948-000 \\ ssfmorghi@gmail.com
}

\begin{abstract}
In Brazil, according to Cnen standard, a nuclear power plant has authorization to operate for 40 years. Angra 1 commercial operation started in 1985 and it has license to operate until 2024. Eletronuclear aims to extend the operation of the Angra 1 plant from 40 to 60 years. To obtain the license renewal by more than 20 years (long-term operation), Eletronuclear will need to meet the requirements of 10 CFR Part 54, Cnen NT-CGRC-007/18 and NT-CGRC-008/18 (Cnen technical notes). To obtain a license renewal to a long-term operation it is necessary to demonstrate that the plants will operate according to safety requirements, through analysis, testing, aging management, system upgrades, as well as additional inspections. Plant operators and regulators must always ensure that plant safety is maintained and, when it is possible, strengthened during the long-term operation of the plant. One of the documents to obtain a license renewal to a long-term operation is the Quality Assurance Program (QAP). Angra 1 has a QAP according to 10CFR 50 App B and Cnen NN 1.16 for safety related items. However, according to 10 CFR50.34, Nureg-1800 Appendix A.2, Nureg-1801 Appendix A-1 of Nuclear Regulatory Commission (NRC) and NT-CGRC-007/18 and NT-CGRC-008/18 of Cnen, the QAP needs to include the items that are not safety related but are included in the Aging Management. This article will discuss the Angra 1 QAP for the license renewal to a long-term operation according the standards approved by Cnen.
\end{abstract}

Keywords: Quality Assurance Program, Angra 1 power station, Cnen, license renewal 


\section{INTRODUCTION}

The commercial operation of Angra 1 started in 1985 and it was licensed by Cnen for operation until 2024. Eletronuclear aims to extend the operation of the Angra 1 plant from 40 to 60 years. To obtain the extension of the plant life by more than 20 years, Eletronuclear will need to meet the requirements of Cnen NT-CGRC-007/18 and NTCGRC-008/18 (Cnen technical notes) [1. 2].

The Cnen technical notes approves the American Standards to the License Renewal, that are 10 CFR50.34, Nureg-1800, Nureg-1801, because Angra 1 is an American project, it was built by Westinghouse. The 10 CFR Part 54 regulation states that the License Renewal request must contain information on:

a) Integrated Plant Assessment (IPA) - Select the scope of the Ageing Management, Elaboration of the Aging Management Review and Aging Management Programs.

b) Revalidation of the Time-limited aging analyses (TLAA).

c) Changes in the current licensing basis, if any, during the evaluation process of the license renewal application.

d) Supplements of the Final Safety Analysis Report (FSAR) describing the aging management program, revalidation of TLAAs, and changes to Technical Specifications.

According to 10 CFR Part 54, the plant must present the documentation to the licensing agency up to 05 years before the end of the license, in the case of Angra 1, this term is until 2019.

According to the Cnen NT07/2018 application for Long-Term Operation (LTO) shall consider the following topics, but not limited to:

- Plant Programs;

- Environmental Equipment Qualification for Electric and I\&C Component (US-N RC 10CFR50.49);

- Maintenance Effectiveness Monitoring Program Assessment (US-NRC 10CFR5 $0.65)$; 
- Ageing Management Review;

- TLAA Revalidation;

- Technological Obsolescence Program;

- Specific Periodic Safety Review related the LTO;

- Final Safety Analysis Report, including the Technical Specification Review;

- Regulations, Codes and Standards Updating;

- A technical assessment of the physical condition of the plant;

- An evaluation of past operating experience at the plant relating to ageing,

- Obsolescence and other safety issues;

- Storage of spent nuclear fuel for long-term operation;

- Radioactive waste management for long-term operation;

- An assessment of the environmental impact of long-term.

- Human Resources, competences and knowledges.

For all these activities is necessary to implement a QAP. For license renewal and longterm operation, the QAP must be according to the 10 CFR50.34, 10 CFR 50 App. B, Appendix A.2 do NUREG-1800, Appendix A-1 Nureg-1801 da Nuclear Regulatory Commission - NRC e Safety Guide NS-G-2.12 da IAEA.

\section{DEFINITIONS}

Some important definitions for the license renewal and long-term operation will be $\mathrm{d}$ escribed below:

Current licensing basis (CLB) [3] is the set of NRC requirements applicable to a specific plant and a licensee's written commitments for ensuring compliance with and operation within applicable NRC requirements and the plant-specific design basis (including all modifications and additions to such commitments over the life of the license) that are docketed and in effect.

Integrated plant assessment (IPA) [3] is a licensee assessment that demonstrates that a nuclear power plant facility's structures and components requiring aging management 
review (AMR) in accordance with 10CFR 54.21(a) for license renewal have been identified and that the effects of aging on the functionality of such structures and components will be managed (through the aging management programs - AMP) to maintain the CLB such that there is an acceptable level of safety during the period of extended operation.

Time-limited aging analyses (TLAA) [3], for the purposes of this part, are those licensee calculations and analyses that:

(1) Involve systems, structures, and components within the scope of license renewal.

(2) Consider the effects of aging;

(3) Involve time-limited assumptions defined by the current operating term, for example, 40 years;

(4) Were determined to be relevant by the licensee in making a safety determination;

(5) Involve conclusions or provide the basis for conclusions related to the capability of the system, structure, and component to perform its intended functions.

(6) Are contained or incorporated by reference in the CLB.

\section{ANGRA 1 LICENSE RENEWAL PROCESS}

The licensing process is based on the Permission for Permanent Operation (AOP), as Cnen NE 1.04.

According to Cnen NE-1.04 the current Permit for Permanent Operation may be extended if based on technical assessments to demonstrate that the effects of aging will be satisfactorily managed during the long-term operation period.

The Angra 1 timeline is shown in Figure 1. 
Figure 1: Angra 1 timeline.

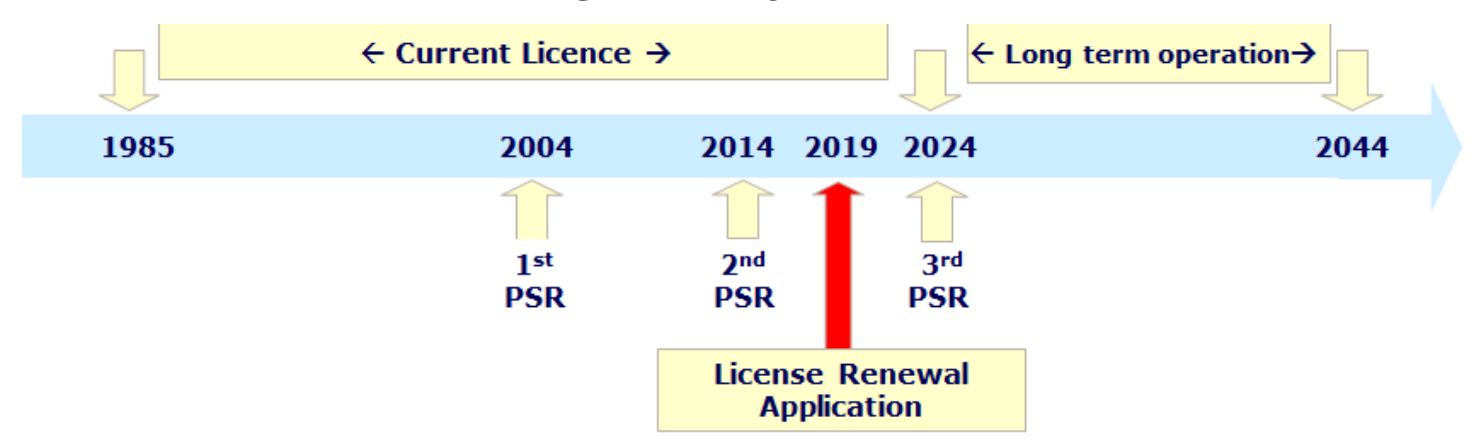

Where :

1985 - Start of commercial operation

2004 - $1^{\text {st }}$ Periodic Safety Review

2014 - $2^{\text {nd }}$ Periodic Safety Review

2019 - License Renewal application

2024 - $3^{\text {rd }}$ Periodic Safety Review

2024 - Expiration of current license and beginning of extended life for 20 years

2044 - Expiration of renewed license

In 2019, Eletronuclear must send to Cnen the License Renewal Application, according to the NT-007/18, the LRA shall contain, at least:

General information about the plant owner or operator.

$>$ IPA, including the methodology used to carry out the ageing management review for long-term operation.

Revalidation of the TLAAs, including exemptions based on TLAAs.

$>$ Annual updates as the plant CLB changes.

$>$ Supplement to FSAR with the summary of AMPs and TLAAs.

$>$ Changes to plant Technical specifications.

$>$ Update of Environmental Information.

All information and conclusions with the regard to the scope of an ageing management review for long-term operation shall be documented including: 
An identification and listing of Structure, System and component (SSC) subject to an ageing management review and their intended functions;

$>$ A description and justification of the methods used to determine the structures or components that are subject to an ageing management review;

$>$ the information sources used to accomplish the above, and any description necessary to clarify their use; and

Demonstration of adequately Ageing Management Effects.

Besides that, an assessment of following programs or activities shall be submitted with the LRA. Demonstrating that the operational safety is assured during the Long-term operation:

$>$ The equipment qualification program;

The effectiveness maintenance monitoring program;

$>$ Operation experience evaluation;

$>$ Obsolescence program;

$>$ Organization structure and

Environmental impact analysis.

Angra 1 have been preparing the LRA according to CNEN NT-007/18, NEI 95-10, 10 CFR 54 and NUREG 1800.

To the long-term operation in Angra 1, following there are some necessary activities and their phases:

- Concluded activities:

- Replacement of the split pins of the Reactor Vessel;

- Replacement of Steam Generators;

- Application of the weld overlay process in the pressurizer nozzles;

- Replacement of the Reactor Vessel Head.

- Implementation of the Fatigue Monitoring Program and Flow Accelerated Corro sion Program;

- Implementation of the Maintenance Rule Program; 
- Implementation of the Periodic Safety Review (carried out in 2004 and 2014);

- Establishment of the structure dedicated to the implementation of the Renewal of Operation License of the Reactor and Long-Term Operation of Angra 1;

- Definition of the policy of the Renewal of Operation License of the Reactor and Long-Term Operation of Angra 1;

- Contracting of Westinghouse - WEC to support ETN in the process of obtaining Angra 1 life extension license;

- Elaborate the Quality Assurance Program for the LTO project and the administra tive procedures.

- Activities in progress:

- Environmental Qualification Program for Electrical Equipment;

- Design of definitive storage of used fuel elements - UAS;

- Realization of Training and Qualification in Aging Management and its Mechani sms;

- WEC Support in preparing the documents for obtaining the long-term operating 1 icense of Angra 1.

- Elaboration of the Ageing Management Review and the Ageing Management Pr ograms.

- Elaboration of the License Renewal Application.

- Activities planned:

- Application of the MSIP process in the reactor vessel nozzles.

\section{QUALITY ASSURANE PROGRAM FOR ANGRA 1 LICENSE RENEWAL AND LONG-TERM OPERATION}

The quality assurance for a nuclear power plant comprises all those planned and systematic actions necessary to provide adequate confidence that a structure, system, or component will perform satisfactorily in service. Quality assurance includes quality control, which comprises those quality assurance actions related to the physical characteristics of a material, structure, component, or system which provide a means to 
control the quality of the material, structure, component, or system to predetermined requirements.

The scope for a Nuclear Power Plant Quality Assurance Program, according to 10 CFR 50 App B and Cnen NN 1.16, is:

Nuclear power plants include structures, systems, and components that prevent or mitigate the consequences of postulated accidents that could cause undue risk to the health and safety of the public. The quality assurance requirements for the design, manufacture, construction, and operation of those structures, systems, and components. The pertinent requirements of a QAP apply to all activities affecting the safety-related functions of those structures, systems, and components; these activities include designing, purchasing, fabricating, handling, shipping, storing, cleaning, erecting, installing, inspecting, testing, operating, maintaining, repairing, refueling, and modifying.

The scope for a License Renewal and Long-term operation, according to 10 CFR50.34, Appendix A.2 do Nureg-1800, Appendix A-1 Nureg-1801 and Safety Guide NS-G-2.12 da IAEA, is:

(1) Safety-related systems, structures, and components relied upon to remain functi onal during and following design-basis events to ensure

(i) the integrity of the reactor coolant pressure boundary;

(ii) the capability to shut down the reactor and maintain it in a safe shutdown condition; or

(iii) the capability to prevent or mitigate the consequences of accidents which could result in potential offsite exposures;

(2) Non-safety related systems, structures, and components whose failure could pre vent satisfactory accomplishment of any of the functions identified above.

(3) Systems, structures, and components relied on safety analyses or plant evaluation $\mathrm{s}$ to perform a function that demonstrates compliance with the regulatory require ments for:

- Fire Protection (FP)

- Environmental Qualification (EQ)

- Pressurized Thermal Shock (PTS) 
- Anticipated Transients Without Scram (ATWS)

- Station Blackout (SBO)

Based on increased scope, the QAP for Angra 1 was revised and it was necessary to create a complementary QAP for the LTO project. According to the IAEA standards the Quality assurance is part of the Integrated Management System [11]: “an integrated management system should provide a single framework for the arrangements and processes necessary to address all goals of the organization. These goals include safety, health, environmental, security, quality and economic elements and others considerations such as social responsibility."

The Angra 1 QAP and the LTO QAP describes how to implement the Basic Requirements according to CNEN NN 1.16.

In Brazil, the Cnen NN 1.16 standard [2] presents 13 requirements, the 18 Basic Requirements of 10 CFR 50 appendix B were reorganized. This standard describes the Quality Assurance Requirements for Nuclear facilities in Brazil and it has the force of law. It applies: "activities affecting quality of items important to safety, developed in each of its various stages: site selection, design, construction, commissioning, operation and decommissioning." (Cnen NN 1.16, 2000, p.4).

Angra 1 NPP were designed and built by Westinghouse, and the Quality Assurance Program during the construction was based on 10 CFR50 App B and ANSI N 45.2 series. The table 1 shows the comparison between the 18 BR of the 10 CFR 50 App B and the Cnen NN 1.16 requirements. 
Morghi et al. • Braz. J. Rad. Sci. • 2021

Table 1: Comparison between the requirements of Cnen NN 1.16 and 18 BR. [10] 10 CFR 50 App B/ NQA-1

Requirements Cnen NN 1.16

I - Organization

4.3

II - Quality assurance program

4.2

III - Design control

IV - Procurement Document control

4.6

$\mathrm{V}$ - Instructions, procedures and

4.1.4

drawings

VI - Document control

VII - Control of purchase material,

equipment, and services

VIII - Identification and control of

materials, parts and components

IX - Control of special processes

$\mathrm{X}$ - Inspection

XI - Test Control

4.9/4.9.2

XII - Control of measuring and test

equipment

XIII - Handling, storage and shipping

XIV - Inspection, test and operation

status

$\mathrm{XV}$ - Nonconforming materials, parts,

or components

XVI - Corrective action

XVII - Quality assurance records

XVIII - Audits

4.13 
Another important change in Angra 1 QAP was the elaboration of the administrative procedures for the LTO project:

Table 2: Administrative procedures for LTO project

\begin{tabular}{ll}
\hline Acronym & \multicolumn{1}{c}{ Title } \\
\hline PA-LG 01 & QAP for LTO project \\
PA-LG 02 & Communication for LTO project \\
PA-LG 03 & Document and records control for LTO project \\
PA-LG 04 & Analyses of AMR, AMP Evaluation, procedures and others documents \\
PA-LG 05 & Elaboration of AMP \\
\hline
\end{tabular}

The PA-LG 05 describes how Angra 1 will introduce the AMP in the operation manual. The AMP should present the follow elements:

Table 3: AMP elements [4]

\begin{tabular}{ll}
\hline \multicolumn{1}{c}{ AMP Element } & \multicolumn{1}{c}{ Description } \\
\hline 1. Scope of the Program & The scope of the program should include \\
& the specific structures and components \\
& subject to an AMR. \\
2. Preventive Actions & Preventive actions should mitigate or \\
& prevent the applicable aging effects. \\
3. Parameters Monitored or Inspected & Parameters monitored or inspected should \\
& be linked to the effects of aging on the \\
& intended functions of the particular \\
& structure and component. \\
4. Detection of Aging Effects & Detection of aging effects should occur \\
& before there is a loss of any structure and \\
component intended function. This & includes aspects such as method or \\
technique (i.e., visual, volumetric, surface
\end{tabular}


5. Monitoring and Trending

6. Acceptance Criteria

7. Corrective Actions

8. Confirmation Process

9. Administrative Controls

10. Operating Experience inspection), frequency, sample size, data collection, and timing of new/one-time inspections to ensure timely detection of aging effects.

Monitoring and trending should provide for prediction of the extent of the effects of aging and timely corrective or mitigative actions.

Acceptance criteria, against which the need for corrective action will be evaluated, should ensure that the particular structure and component's intended functions are maintained under all current licensing basis (CLB) design conditions during the period of extended operation.

Corrective actions, including root cause determination and prevention of recurrence, should be timely.

The confirmation process should ensure that preventive actions are adequate and that appropriate corrective actions have been completed and are effective.

Administrative controls should provide a formal review and approval process.

Operating experience involving the AMP, including past corrective actions resulting in program enhancements or additional programs, should provide objective evidence to support a determination that 
the effects of aging will be adequately managed so that the structure and component intended functions will be maintained during the period of extended operation.

For QAP the elements 7, 8, 9 and 10 are very important, because of the scope of LTO project, some SSC that was not considered in the Angra 1 QAP was incorporated. This means that all SSC of the LTO scope needs to meet the requirements of the Cnen NN 1.16. In addition, it was necessary to develop the methodology of the confirmation process.

Other important change in the QAP are:

The identification of the SSC of the LTO scope in the drawing, procedures, main tenance program, purchase order.

$>$ The implementation of a methodology to identify when a design change affects a $\mathrm{n}$ SSC of the LTO scope, because, maybe, it will be necessary to review the AM $\mathrm{R}$ and AMP.

$>$ Inclusion of audits about the LTO project in the audits program of Eletronuclear.

$>$ Perform the audits about the LTO project.

The results of the audits show that Eletronuclear have been implementing the LTO activities according the international standards and technical notes of Cnen, however it was identified some opportunities for improvement. 


\section{CONCLUSIONS}

Angra 1 started the License Renewal and LTO project according the international standards and technical notes of Cnen.

The QAP program for Angra 1 was reviewed to include the LTO program, in addition it was developed a QAP for the LTO project.

Angra 1 QAP and LTO QAP follow the requirements of Cnen NN 1.16 that are the same as 10CFR50 Appendix B.

For the elaboration of the AMP it was necessary to elaborate a procedure to describe how to implement the 10 elements. It was necessary to improve three elements: the corrective action, administrative control and operating experience. Besides it was necessary to develop the methodology for the confirmation process. These four elements are part of the QAP for Angra 1 and for the LTO project. 


\section{ACKNOWLEDGMENT}

This work was supported by the following Brazilian institutions: Nuclear Technology Development Centre (CDTN), Brazilian Nuclear Energy Commission (Cnen), Research Support Foundation of the State of Minas Gerais (Fapemig), Brazilian Council for Scientific and Technological Development (CNPq, program PEC-EG and Eletrobrás Termonuclear S.A. (Eletronuclear).

\section{REFERENCES}

[1] COMISSÃO NACIONAL DE ENERGIA NUCLEAR, - Regulatory Requirement s for Long-term Operation for Nuclear Power Plants. NT-CGRC-007/2018.

[2] COMISSÃO NACIONAL DE ENERGIA NUCLEAR, - Regulatory Positions for Ageing Management in Nuclear Power Plants. NT-CGRC-008/2018

[3] U.S. NUCLEAR REGULATORY COMMISSION. Requirements for Renewal of Operating Licenses for Nuclear Power Plants - 10 CFR PART 54. Available at: https://www.nrc.gov/reading-rm/doc-collections/cfr/part054/. Page Last Reviewed/U pdated, July 19th, 2019.

[4] U.S. NUCLEAR REGULATORY COMISSION. Standard Review Plan for Revie w of License Renewal Applications for Nuclear Power Plants - Final Report (N UREG-1800, Revision 2). Available at: https://www.nrc.gov/reading-rm/doc-collecti ons/nuregs/staff/sr1800/r2/. Page Last Reviewed/Updated, July 19th, 2019.

[5] U.S. NUCLEAR REGULATORY COMISSION. Standard Review Plan for Revie w of License Renewal Applications for Nuclear Power Plants - Final Report NU REG-1800, Revision 2. Available: https://www.nrc.gov/reading-rm/doc-collections/ nuregs/staff/sr1800/r2/. Page Last Reviewed/Updated, July 19th, 2019.

[6] U.S. NUCLEAR REGULATORY COMISSION. Generic Aging Lessons Learned (GALL) Report (NUREG-1801). Available at: https://www.nrc.gov/reading-rm/doc -collections/nuregs/staff/sr1801/, Page Last Reviewed/Updated, July 19th, 2019. 
[7] U.S. NUCLEAR REGULATORY COMISSION. Quality assurance criteria for N uclear Power Plant - 10 CFR 50 appendix B. Available at: http://www.nrc.gov/read ing-rm/doc-collections/cfr/part050/part050-appb.html. Page Last Reviewed/Updated , July 19th, 2019.

[8] ASME. Quality Assurance Requirements for Nuclear Facility Applications. AS ME Boiler Pressure Vessel. Norma NQA-1. Editions from 1994 and 2008. 2009.

[9] COMISSÃO NACIONAL DE ENERGIA NUCLEAR,. Licenciamento de Instalaç ões Nucleares, Norma NE 1.04.

[10] BALIZA, A. R. The 18 Basic Requirement of Quality Assurance for American design NPP. In: INTERNATIONAL NUCLEAR ATLANTIC CONFERENCE INAC 2013, Recife, PE, Brazil, November 24-29, 2013.

[11] INTERNATIONAL ATOMIC ENERGY AGENCY. Application of the Manag ement System for Facilities and Activities - Safety Guide No GS-G-3.1. Available at: https://www-pub.iaea.org/MTCD/Publications/PDF/Pub1252_web.pdf, Page Last Reviewed/Updated, July 19th, 2019.

[12] INTERNATIONAL ATOMIC ENERGY AGENCY. Ageing Management for Nuclear Power Plants - Safety Guide NS-G-2.12. Available at: https://www.iaea.or g/publications/8083/ageing-management-for-nuclear-power-plants, Page Last Revie wed/Updated, July 19th, 2019.

[13] NUCLEAR ENERGY INSTITUTE. Industry Guideline for Implementing the Requirements of 10 CFR Part 54 - The License Renewal Rule - NEI 95-10. Avai lable at: https://www.nrc.gov/docs/ML0518/ML051860406.pdf, Page Last Reviewed /Updated, July 19th, 2019. 